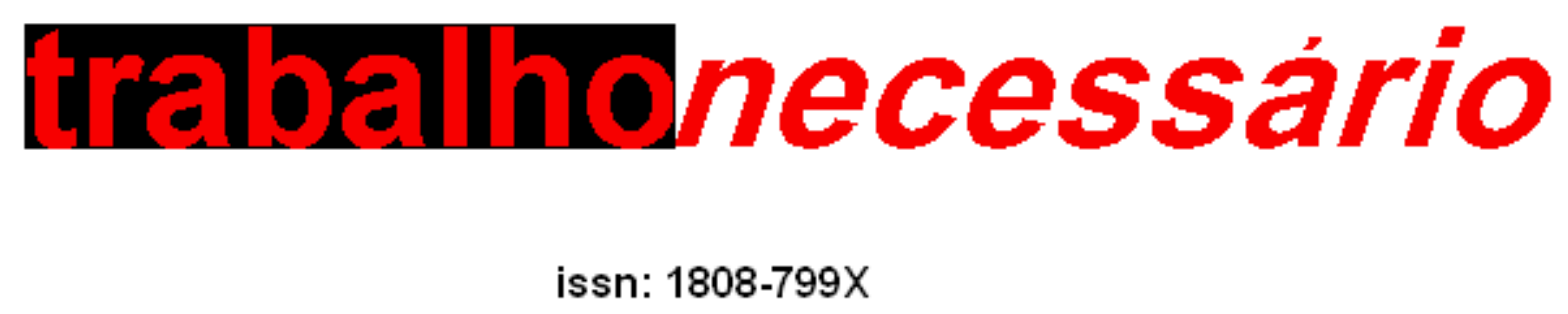

ano 4 - número 4 - 2006

\title{
ORGANISMOS INTERNACIONAIS E O MANIFESTO DA EDUCAÇÃO HEGEMÔNICA DO CAPITAL
}

Elenilce Gomes de Oliveira[i]

elengomes@bol.com.br

Este escrito evidencia a concepção dos organismos internacionais referente ao ensino médio e profissional. Cabe ressaltar que não se trata de enveredar na discussão sobre a imposição ou influência nas políticas do Governo federal brasileiro, mas de trazer para análise alguns elementos relativos à educação presentes nas publicações do Banco Mundial e da Comissão Especial para a América Latina - CEPAL. Em linhas gerais, os diversos documentos elaborados por esses organismos apontam uma concepção de educação restrita ao mercado, cuja eficiência se relaciona ao funcionamento das parcerias público-privado. Dessa maneira, cumpre destacar que a educação hegemônica do capital tem como eixo a sua funcionalidade instrumental à competição entre os trabalhadores e entre países.

\section{O Banco Mundial e a CENTRALIDAde da educaçÃo no DESENVOlVIMENTO dos Países}

O Banco Mundial foi criado em 1946, com a finalidade de reconstrução e desenvolvimento dos países atingidos pela Segunda Guerra Mundial por meio de empréstimos para gastos públicos em infra-estrutura, expandindo mercados para os EUA. No contexto da Guerra-Fria, o banco estendeu seus empréstimos e assistência técnica aos países das regiões consideradas subdesenvolvidas ou periféricas, evitando, assim, a adesão desses países ao comunismo.

O Banco Mundial centrou seu raio de ação na infra-estrutura física construção, reconstrução de vias para transporte, provimento de energia e comunicação. Nas décadas de 1980 e 1990, ocorreram mudanças relativas às estratégicas do banco, intensificando-se 0 interesse em conceder empréstimo às áreas concernentes às necessidades básicas, a fim de que os pobres se identificassem, sobretudo, pela ausência ou dificuldade de acesso à alimentação, saúde e educação, encobrindo a identificação da 
pobreza a determinada região ou classe social. Entre essas necessidades básicas, o banco destacou a educação, de modo que em sua agenda foram estabelecidas três grandes metas em torno da ampliação do acesso à educação formal, eficiência dos sistemas educacionais e racionalização dos recursos financeiros na operacionalização dessas metas.

No âmbito do Banco Mundial, education is central to development (BANCO MUNDIAL, 2005). A educação, neste sentido, torna-se requisito inequívoco para que os demais países alcancem o patamar dos mais ricos, tratando-a como instrumento técnico capaz de elevar a condição dos países que não estão à frente do poderio econômico. Vale ressaltar que o Banco não se refere a qualquer educação, pois há um tipo especificamente recomendado, sendo necessárias reformas no sistema educativo dos países que desejam obter posição privilegiada no mercado internacional. A educação a qual o Banco se refere é aquela dirigida a determinada população com fins nitidamente voltados para a inserção no mercado de trabalho.

No documento Estratégias de Assistência ao Brasil para 2004-2007, o BM sugere que o crescimento econômico requer, além de maior volume de poupança, medidas que permitam um papel mais atuante dos excluídos do desenvolvimento humano e das pequenas e médias empresas no processo de crescimento, os ganhos de produtividade poderão ser mais elevados e eqüitativos (Banco Mundial, 2003, p.01).. Destaca-se, portanto, o enfoque na educação como estratégia necessária ao crescimento econômico, sendo decisivo o seu papel na elevação da competitividade entre os países e entre os integrantes do País.

O BM reconhece, de um lado, o esforço dos países que, como o Brasil, elevou o acesso à educação e, de outro, chama a atenção para a necessidade de reduzir o ônus da escola, que se acentua em decorrência do elevado número de reprovação e evasão dos alunos. O desafio a ser enfrentado, com a finalidade de redução de custos, é a baixa qualidade do desempenho da escola, expresso na pífia performance dos alunos. Alicerçados neste raciocínio, os assessores do banco destacam os fatores que contribuem para a baixa qualidade e, conseqüentemente, para a elevação do ônus da escola. Em documento de 2000, denominado $A$ educação secundária no Brasil: chegou a hora, o Banco explicita que a "escola de baixa qualidade não só é menos atraente quando comparada com a participação na força de trabalho, mas também é mais cara."(Worldbank, 2000, p.78). Dessa maneira, o Banco expressa, sobretudo, o seu pensamento racional-financeiro em torno da educação.

Ao apontar os problemas e os desafios do ensino médio no Brasil, o BM se refere ao ensino de $5^{\mathrm{a}}$ a $8^{\mathrm{a}}$ série - entendido pelo $\mathrm{BM}$ como o primeiro ciclo do ensino secundário - enfatizando os fatores intra-escolares que prejudicam a aprendizagem dos alunos. Em relação aos fatores que influem na baixa qualidade do ensino, o BM destaca o material didático, instalações inadequadas, pouca experiência dos professores, cansaço dos alunos do turno noturno. Outros aspectos não foram considerados relevantes, tais 
como gestão colegiada, tamanho da classe e deveres de casa. Em relação ao ensino médio, tornam-se importantes a existência de laboratórios e professores com conhecimentos específicos sobre a matéria.

Entre as recomendações expressas no documento $A$ educação secundária no Brasil: chegou a hora, estão o estímulo à freqüência às aulas, sobretudo, das escolas noturnas, a implantação das Diretrizes Curriculares Nacionais, a parceria público-privada em que as escolas privadas cedam, vez por outra, as suas instalações e realizem treinamento para os professores das escolas públicas. Outras sugestões dizem respeito à gestão direta dos recursos financeiros, permitindo que as escolas definam as suas prioridades e realizem as compras de materiais apropriados à idade dos alunos; aumento da jornada escolar aos alunos do turno noturno e das regiões de difícil acesso por meio de ensino à distância e cursos de finais de semana; treinamento para professores e gestores; envolvimento da comunidade na manutenção das instalações da escola; definição de padrões mínimos para o funcionamento das escolas em relação a material, livros, instalações, ventilação, iluminação, recursos humanos.

Em relação ao financiamento dessa melhoria da qualidade da escola, o BM sugere duas saídas não-excludentes: a primeira é a otimização dos recursos existentes, reduzindo a ineficiência e evitando-se a repetência no ensino fundamental; a segunda, de curto prazo, são os empréstimos internacionais, a criação do fundeb, o estímulo aos estados que apliquem um mínimo de suas despesas no ensino médio em troca de descontos nas contribuições ao fundef, a parceria público-privado em que o Governo federal oferece subsídios às escolas privadas para abertura e credenciamento de escolas recebendo, em contra-partida, a permissão para uso de sua infra-estrutura e o treinamento de seus professores (WORLDBANK, 2000).

Os grandes desafios para o ensino médio, segundo o BM, são, basicamente, quatro: redução dos índices de repetência e desistência; expansão do acesso para estudantes de área rural; melhoria da qualidade do ensino e; financiamento da expansão do ensino. Dessa maneira, a ênfase aos fatores intra-escolares evidencia a concepção estreita de educação do Banco, interessando somente aquela dirigida à racionalização dos gastos e à eficiência em relação às necessidades do mundo competitivo, implicando em que qualquer outro tipo de educação deve ser dispensado, vez que a preocupação é a formação de capital humano.

No documento Brasil justo, sustentável e competitivo: contribuições para o debate, elaborado em 2003, a apreciação do BM é de que, entre 1996 e 2001, o Brasil fez a sua tarefa de casa, aumentando extraordinariamente o número de matrículas de alunos com idade entre 07 a 14 anos. Da mesma forma, a educação infantil teve crescimento, aumentando de 328 mil para 1 milhão de crianças em creches (0-3 anos); a educação ao passo que o ensino médio registrou 8.5 milhões de jovens contra 5.7 milhões no início do período. Ainda nesse documento, o BM ressalta a redução da repetência, chamando atenção para a economia de 240 milhões de dólares para cada percentual a menos de 
crianças retidas nas primeiras quatro séries; destaca o problema do desempenho dos alunos evidenciado no Sistema de Avaliação da Educação Básica SAEB; e considera que essa performance ocorre por motivos relacionados à pobreza da instrução dos alunos no primeiro ano escolar; inadequação das metodologias dos professores às condições de cansaço dos alunos trabalhadores; relevância do conteúdo aos alunos as escolas noturnas; e à prática de estabelecer notas como instrumento de controle da qualidade da aprendizagem.

Em relação ao financiamento da expansão do ensino médio e melhoria de sua qualidade, o Banco ressalta, no documento Brasil justo, sustentável e competitivo: contribuições para o debate, a positividade da criação do Fundo de Manutenção do Ensino Fundamental e Valorização do Magistério - Fundef, criticando, por outro lado, o problema da eficiência dos gastos que se perdem no elevado número de alunos repetentes e evadidos; e sugere a criação do fundeb, a oferta de subsídios por parte do governo federal aos estados que invistam o mínimo de suas despesas por estudante matriculado neste ensino, de modo que tais estados recebam descontos sobre suas contribuições no fundef.

Além da ênfase à eficiência do ensino e dos seus gastos, o BM considera que o Brasil necessita dirigir o ensino médio à formação de habilidades, permitindo aos jovens o desenvolvimento de capacidades para toda a vida. Isto implica, segundo o Banco, um ensino médio que não enfatize a formação de habilidades específicas e privilegie os aspectos da capacidade de tomar decisões e resolver problemas.

Ainda no documento Brasil justo, sustentável e competitivo: contribuições para o debate, o BM se refere ao ensino superior, retomando a preocupação com a eficiência acrescida de uma suposta necessidade de mudança na formação a fim de acompanhar as habilidades exigidas pelo trabalho desenvolvido por profissionais de nível superior. Segundo o Banco, os ganhos com uma reforma no ensino superior são enormes porque "ajudaria encontrar uma grande demanda por capital humano avançado, acelerando o avanço tecnológico, a competitividade e crescimento da economia no Brasil" (Worldbank, 2003, p. 150. Tradução nossa).

\section{A Comissão especial para a América latina e Caribe e a educação como ESTRATÉGIA PARA O DESENVOLVIMENTO}

A Comissão Especial para a América Latina e Caribe coordena projetos junto aos governos do circuito latino-americano e caribenho e inclui a educação como uma das principais estratégias para o desenvolvimento. Instituída em 1948, no contexto da independência de antigas colônias, às quais se mostraram insatisfeitas com desigualdades das relações econômicas no mercado internacional, a sua tarefa principal consistiu em explicar as vantagens dos países centrais em relação aos outros, sustentando o argumento de que os países pobres precisavam passar por etapas, a fim de atingir patamar dos países ricos. A CEPAL adverte, porém, que essa passagem não ocorre tranquilamente, vez que a riqueza de alguns mantém vínculo com a pobreza de outros países. 
A CEPAL se concentrou na formulação de medidas consideradas necessárias ao alcance do desenvolvimento. Dos anos 1960 até os dias atuais, em seus escritos, as políticas sociais foram, enfaticamente, consideradas imprescindíveis ao desenvolvimento econômico, destacando-se, no plano da educação formal, a educação primária, secundária e profissional, que se destacam nas recomendações cepalinas em razão de sua capacidade de contribuir na mudança de padrões de consumo, no uso da tecnologia etc. A educação básica e profissional, desta maneira, ocupou posição privilegiada nos seus escritos, sendo considerada como a potencialidade capaz de levar a América Latina a enfrentar o mercado mundial.

No documento Educación y conocimiento: eje de la transformación productiva con equidad, produzido em 1992, a CEPAL retoma a importância do progresso técnico à produção e enfatiza as políticas redistributivas focalizadas no combate à pobreza, destacando o papel da educação e do conhecimento como meios para a transformação produtiva, sendo que a incorporação e difusão do progresso técnico devem funcionar como a mola desta transformação. A incorporação e a difusão do progresso técnico, na perspectiva cepalina, requer também considerar outros fatores, tais como la creciente apertura a la economia internacional y, muy especialmente, la formación de recursos humanos y el conjunto de incentivos e mecanismos que favorecen el acceso y la generación de nuevos conocimientos (CEPAL, 1992, p.01). O objetivo é criar condições educacionais que permitam capacitação e incorporação do progresso técnico, modernizando as estruturas produtivas destes países, tendo em conta a eqüidade social. Essas condições educacionais somente seriam proporcionadas mediante reformas dos sistemas educativos e capacitação para o emprego.

No segundo documento produzido em 1996 - Eqüidad y transformación productiva: um enfoque integrado, a CEPAL enfatizou a complementaridade entre transformação produtiva e eqüidade social e destacou o vínculo entre educação e desenvolvimento, bem como a necessidade dos países latino-americanos enfrentarem desafios relacionados à consolidação da democracia, da coesão social e da eqüidade, e encontrarem meios de enfrentar a competitividade internacional como forma de acesso a bens e serviços modernos.

Este documento, portanto, reforça o anterior, inclusive no que diz respeito à necessidade de reformas educacionais, destacando a ineficiência dos sistemas de ensino, quantitativa e qualitativamente. Tais reformas cumpririam a missão de retirá-los do seu isolamento em relação ao mercado e aos novos códigos da Modernidade, além de proporcionar valorização dos educadores e viabilizar o compromisso financeiro da sociedade com a educação.

No documento Equidad, desarrollo y ciudadanía, elaborado em 2000, a CEPAL exprime o que espera da educação: contribuição para a eqüidade, competitividade e cidadania. Ao analisar as mudanças na década de 1990, destaca a fragilidade do sistema educacional latino - americano e caribenho com o mercado produtivo, apontando o 
fato de que o sistema educativo há tenido poca conexión con la evolución del sistema productivo y con las transformaciones que ocurrían en la sociedad (...). (2000, p. 93). Considerando este requisito imprescindível ao desenvolvimento, a CEPAL considera que este desafio não pode ser adiado, pois essa exigência decorre da evolução da ciência e tecnologia.

A análise cepalina sobre a situação educacional dos países latino-americanos destaca a problemática do elevado índice de evasão na escola primária e a discrepância entre a zona rural e urbana no tocante ao acesso e ao desempenho escolar, bem como a insuficiência de vagas no ensino superior. A CEPAL recomenda que os países periféricos garantam o cumprimento de cerca de 10 a 12 anos de estudos - o equivalente à conclusão do ensino médio - a fim de evitar o empobrecimento. A análise da Comissão não busca as causas dos problemas, apontando soluções superficiais e paliativas: ampliação de oferta de vagas e oportunidades aos que se encontram econômico-socialmente em desvantagem e vinculação dos objetivos formativos aos "requisitos" do mercado produtivo. Em se tratando dos sistemas educativos, sugere adequación de los sistemas educativos a las exigencias productivas y la competitividade global basada en la incorporación de progreso técnico. (2000, p. 95).

A Comissão enfatiza a importância da cobertura desde a educação préescolar até o término do ensino secundário para alcanzar una alta probabilidade de no caer en la pobreza (2000, p.17). A educação, porém, somente poderá atuar sobre a redução da pobreza se houver geração de empregos. Reconhecendo aí a maior dificuldade, a CEPAL volta-se para as reformas do Estado, no sentido de que ofereça maior espaço para a iniciativa privada, propiciando a sua participação na gestão de entidades públicas, especialmente de seguridade social, garantindo assim a eficiência.

Desta maneira, ainda segundo o entendimento cepalino, os países devem priorizar áreas de mayor efecto redistributivo: educación primaria y secundaria, salud y nutrición (2000, p.18). Considerando que os níveis de tributação de alguns países da América Latina estão abaixo dos padrões internacionais, a CEPAL recomenda a ampliação da base tributária, desde que isto seja realizado a longo prazo. A recomendação em ampliar a base tributária permitiria ao Estado contar com fluxo quantitativamente mais elevado de recursos, cobrindo os gastos das áreas mencionadas.

Os anos 1990 revelam a adesão do pensamento cepalino aos preceitos do neoliberalismo, substituindo a enorme influência keynesiana, que marcou as recomendações dos anos 1940-1960. Na atualidade, portanto, mais do que identificação com o projeto neoliberal, suas orientações se apóiam, também, na proposta do desenvolvimento solidário da socialdemocracia, no sentido de que a sociedade civil se mantenha alerta e predisposta a oferecer seus préstimos aos casos extremos de pobreza, uma vez que o Estado, sob as vestes neoliberais, abandonou a função de provedor.

A educação profissional de nível médio ou superior - vista do ângulo do Banco Mundial e CEPAL - direciona-se às necessidades do mercado e sua eficiência 
relaciona-se à capacidade do pleno funcionamento das parcerias públicoprivado. Neste sentido, a educação hegemônica do capital se centra na sua funcionalidade instrumental à competição entre os trabalhadores e entre países, permanecendo envolta nos meandros da teoria do capital humano. A manifestação desses aspectos da educação hegemônica do capital não estaria cumprindo a função de controle das tensões sociais que poderiam ser desencadeadas pelo crescente aumento da pobreza?

\section{Referências bibliográficas}

Banco Mundial. 2005. Empréstimo programático de reforma do setor de desenvolvimento humano. Disponível em: <http//:www.obancomundial.org.br/index.php>. Acesso: 18 set. 2005.

CEPAL. 1992. Educación y conocimiento: eje de la transformación productiva com eqüidad. Disponível em: <http//:www.cepal.org.br>. Acesso: 15 abr. 2005.

2000. Eqüidad, desarrollo y ciudadanía. Disponível em: <http/:www.cepal.org.br>. Acesso: 15 abr.2006.

Worlbank. 2005. Education and Development. Disponível em: $<$ http//www.worldbank.org.br>. Acesso: 18 set. 2005.

. 2000. A Educação secundária no Brasil: chegou a hora. Worldbank. Disponível em: <http//www.worldbank.org.br>. Acesso: 05 mai. 2006.

2003. Brasil justo, sustentável e competitivo: contribuições para o debate. Worldbank. Disponível em: <http//www.worldbank.org.br>. Acesso: 20 mai. 2006.

[i] Elenilce Gomes de Oliveira; doutoranda em educação; pedagoga no Centro Federal de Educação Tecnológica do Ceará; bolsista da FUNCAP.

\section{volta}

